\title{
Comparison of different concentrations of levobupivacaine for post-operative epidural analgesia
}

\author{
M. Dernedde, M. Stadler, F. Bardiau and J. Boogaerts \\ Department of Anaesthesiology, University Hospital Centre, Charleroi, Belgium
}

\begin{abstract}
Background: The relative effects of the mass, volume and concentration of local anaesthetic solution used for epidural anaesthesia and analgesia are still under debate. Clinical studies have shown discrepancies, probably because of limited consideration of total dose.

Methods: This prospective, randomized and blinded study evaluated the spread, the quality of post-operative analgesia and the incidence of side-effects of continuous thoracic epidural levobupivacaine $15 \mathrm{mg} / \mathrm{h}$ in three different concentrations: $1.5 \mathrm{mg} / \mathrm{ml}, 10 \mathrm{ml} / \mathrm{h}(n=26), 5 \mathrm{mg} / \mathrm{ml}, 3 \mathrm{ml} / \mathrm{h}(n=33)$ or $7.5 \mathrm{mg} / \mathrm{ml}, 2 \mathrm{ml} / \mathrm{h}(n=31)$. The following variables were registered within $48 \mathrm{~h}$ : sensory block, pain scores, rescue morphine consumption, motor blockade, haemodynamics, sedation, nausea and vomiting, and patient satisfaction.

Results: The three groups were similar with regard to demographics, quality of analgesia, morphine consumption, and satisfaction rate. The upper level of sensory block was two segments higher in the $1.5 \mathrm{mg} / \mathrm{ml}$ group. Motor blockade in
\end{abstract}

the lower limbs was low in the three groups. Haemodynamic profile was more stable in the higher concentration groups compared with the $1.5 \mathrm{mg} / \mathrm{ml}$ patient group $(P<0.001)$ Nausea was more frequent in the $1.5 \mathrm{mg} / \mathrm{ml}$ group $(P=0.02)$. Conclusion: The same dose of levobupivacaine provides an equal quality of analgesia in low or high volume continuous thoracic epidural infusion with reduced haemodynamic instability and nausea in the low volume/high concentration groups.

Accepted for publication 9 April 2003

Key words: local anesthetics; levobupivacaine; dose; concentration; pain; post-operative; anesthetic techniques; epidural.

(C) Acta Anaesthesiologica Scandinavica 47 (2003)
$\mathrm{T}$ HE relative effects of the mass, volume and concentration of local anaesthetic solution used for epidural anaesthesia and analgesia are still under debate. In clinical studies (1-5), discrepancies appeared probably caused by the fact that the total dose of local anaesthetic was not taken into consideration. Bromage (6) found that it is the total local anaesthetic dose, and not the total volume, that determines the spread and quality of analgesia. This has been confirmed by others, after both lumbar (7) and mid-thoracic (8) epidural administration. For continuous thoracic epidural administration, Dernedde et al. (9) demonstrated in a pilot study, that a high concentration/low volume of local anaesthetic provided equal quality of post-operative analgesia as a low concentration/high volume infusion and induced less motor blockade and haemodynamic repercussions. Nevertheless, it remains debatable in

The research has been performed in the Department of Anaesthesiology, University Hospital Centre of Charleroi, Belgium without any financial support. literature, whether the concentration influences the quality of pain relief during epidural analgesia, as long as the total dose is constant (10-12).

To confirm the findings that the spread and the quality of epidural analgesia depend on the total mass of local anaesthetic and not on the volume or concentration, we designed a prospective, randomized and blinded study to compare three different concentrations of levobupivacaine $(1.5,5$ and 7.5 $\mathrm{mg} / \mathrm{ml}$ ), given as an equal hourly dose continuous infusion after lower abdominal surgery.

\section{Methods}

After approval by the Ethics Committee, written informed consent was obtained from 99 consecutive ASA physical status I to III patients undergoing elective lower abdominal surgery. Patients were included if they were 18-75years old, able to read and understand French, with normal mental health and hospitalized for elective surgery. Exclusion 
criteria were sepsis, allergy to amide-type local anaesthetics or morphine and coagulopathy. At the time of the pre-operative visit, patients were familiarized with a $10-\mathrm{cm}$ visual analogue scale (VAS) device for pain $(0=$ no pain at all, $10=$ worst imaginable pain $)$ and nausea $(0=$ no nausea at all, $10=$ worst imaginable nausea) intensity assessment (13).

Patients were premedicated with midazolam 3-6 $\mathrm{mg}$ administered intramuscularly $1 \mathrm{~h}$ before induction of anaesthesia or alprazolam $0.5-0.75 \mathrm{mg}$ orally in the morning of the intervention. In the operating room, after infusion of $500 \mathrm{ml}$ of Ringer's lactate solution via an intravenous canula, a 20-gauge epidural catheter was inserted through an 18-gauge Tuohy needle into the epidural space at low thoracic levels. The epidural catheter was directed cephalad for a distance of $4 \mathrm{~cm}$ and fixed to the back of the patient. As soon as the patient was in a supine position, a test dose of $3 \mathrm{ml}$ of $5 \mathrm{mg} / \mathrm{ml}$ levobupivacaine (Chirocaine ${ }^{\circledR}$, Abbott, Belgium) was injected through the catheter $(14,15)$. Bilateral sensory anaesthesia was demonstrated by pinprick after the test dose.

Anaesthesia was maintained with sevoflurane in $50 \%$ oxygen in air or nitrous oxide associated with sufentanil and myorelaxant. Based on an anti-emetic institutional policy (16), tropisetron $\left(\right.$ Novaban $^{\mathbb{R}}$, Novartis, Brussels, Belgium) $2 \mathrm{mg}$ was administered to all patients. Three to $6 \mathrm{ml}$ of $5 \mathrm{mg} / \mathrm{ml}$ levobupivacaine was injected through the epidural catheter for the surgical procedure. If surgery lasted longer than $2 \mathrm{~h}$, patients received a reinjection of half of the volume of the local anaesthetic using the same concentration. After completion of the operation and tracheal extubation, patients were transferred to the post-anaesthesia care unit (PACU) where they remained under constant observation for approximately $4 \mathrm{~h}$. The patients received in a random fashion using a computer-generated random number table, $1.5 \mathrm{mg} / \mathrm{ml}$ levobupivacaine $10 \mathrm{ml} / \mathrm{h} \quad(n=31)$, $5 \mathrm{mg} / \mathrm{ml}$ levobupivacaine $3 \mathrm{ml} / \mathrm{h} \quad(n=33)$ or $7.5 \mathrm{mg} / \mathrm{ml}$ levobupivacaine $2 \mathrm{ml} / \mathrm{h}(n=35)$ for postsurgical pain relief via an infusion pump (Abbott aim ${ }^{\mathbb{R}}$ plus, Abbott Laboratories, North Chicago, IL). No extra bolus injection or change of the infusion rate was allowed. Patients received multimodal analgesia consisting of 6-hourly intravenous propacetamol (2 g) and ketorolac (60 $\mathrm{mg}$ daily) for postoperative pain relief. Rescue medication by means of morphine was provided via a patient-controlled analgesia device (Abbott Lifecare PCA Infusor, Abbott Laboratories) with 1.5-mg bolus doses, a 7-min lockout time, and a 25-mg dose limit over $4 \mathrm{~h}$ without loading dose. The consumption of analgesic drugs was recorded during the 48 -h study period. After $48 \mathrm{~h}$, the infusion of levobupivacaine was discontinued and alternative analgesia was provided.

Upon arrival in the PACU, patients were asked to rate their pain experience on the VAS device. This process was repeated every $2 \mathrm{~h}$ for the first $4 \mathrm{~h}$, and when the patient moved to the general surgical ward, it was continued every $4 \mathrm{~h}$ for $48 \mathrm{~h}$. Only rest pain was assessed, defined as the pain experienced by the patient while lying in bed. The pain threshold was set at $3 \mathrm{~cm}$ on the VAS scale (17). Nausea intensity was evaluated using a VAS device and vomiting was recorded as either present or absent by direct observation or by spontaneous complaint of the patient. Nausea was defined as a patient's rating score superior to $4 \mathrm{~cm}$ on the VAS (13). Rescue medications given for nausea and/or vomiting were recorded. Motor blockade in the lower limbs was assessed according to a modified Bromage scale (18) $(0=$ no motor block, $1=$ inability to flex hips, $2=$ inability to flex knees, $3=$ inability to flex ankle joints). The cephalad level of sensory block was evaluated by loss of sensation to cold using ether swabs at the same time. If the levels of sensory block on the right and left sides were different, the most cephalad was recorded. Nurses, who were blinded to the type of epidural solution, collected the data.

Hypotension was defined as a $30 \%$ decrease of systolic blood pressure compared with baseline, bradycardia as heart rate inferior to $50 \mathrm{bpm}$, and bradypnea as a respiratory rate less than 10 breaths/min. Sedation was recorded on a 4-point scale $(0=$ no signs of sedation, $1=$ mild sedation, $2=$ moderate sedation, $3=$ severe sedation).

During the first $48 \mathrm{~h}$, the patients were visited by a pain nurse from the Acute Pain Service and interviewed regarding satisfaction with post-operative analgesia. The patient judged the quality of pain management using a 4-point scale $(1=$ very dissatisfied, $2=$ dissatisfied, $3=$ satisfied, $4=$ very satisfied).

\section{Statistical analysis}

Results were expressed as means \pm SDs for quantitative variables and as frequencies for categorical findings. Time-related VAS measurements were summarized using different pain indicators as described elsewhere (17): AUC: area under the VAS time curve $\left(\mathrm{cm}^{2}\right)$; mean VAS $(\mathrm{cm})$; VAS max: peak of VAS (cm); Tmax: time of VAS max (h); PVAS > 3: the persistence of VAS over $3 \mathrm{~cm}$, i.e. the time period during which VAS was above the critical threshold (h); Pdur: pain duration, i.e. the time period during which the patient reported pain (VAS $>0$ ) over the 


\section{Dernedde et al.}

$48 \mathrm{~h}(\mathrm{~h})$. The comparison of mean values was done using the ANOVA test, whereas proportions were compared using the classic $\chi^{2}$-test. The general linear model (GLM) was used to analyse repeated measures of continuous data. The GLM tests two null hypotheses as follows: (1) time has no effect on the variable, which means that the variable mean of the combined groups does not vary over time; and (2) the time patterns are equal between the three groups, which means that the difference between the mean of each group is the same at every time-point. Bonferroni's test, based on Student's t-statistic, was used for post hoc testing. The number of patients included in the study was based on our previous results and on a power calculation assuming a $20 \%$ difference with $\alpha=0.05$ and $\beta=0.20(9,19)$. All statistical calculations were carried out by means of the SAS package (SAS Institute, Cary, NC, version 6.12) and always using all data available. Results were considered to be significant at the $5 \%$ critical level $(P<0.05)$.

\section{Results}

Nine patients were excluded due to protocol deviation, lack in data recording or accidental removal of the catheter. A total of 90 patients with complete case report forms were included in the study (26 in the $1.5 \mathrm{mg} / \mathrm{ml}$ group, 33 in the $5 \mathrm{mg} / \mathrm{ml}$ group and 31 in the $7.5 \mathrm{mg} / \mathrm{ml}$ group). In these patients, epidural catheters were functioning until the end of the observation period. Patients' characteristics and distribution according to the type of surgery are displayed in Table 1. The demographic data baseline recordings and the type of surgery were similar in the three

Table 1

Demographic and type of surgery in the three groups. Concentration $\left(\mathrm{mg} \mathrm{m}^{-1}\right)$ refers to levobupivacaine.

\begin{tabular}{lcccc}
\hline Variable & $\begin{array}{c}1.5 \mathrm{mg} / \mathrm{ml} \\
(n=26)\end{array}$ & $\begin{array}{c}5 \mathrm{mg} / \mathrm{ml} \\
(n=33)\end{array}$ & $\begin{array}{c}7.5 \mathrm{mg} / \mathrm{ml} \\
(n=31)\end{array}$ & $P$-value \\
\hline Sex (M/F) & $8 / 18$ & $14 / 19$ & $7 / 24$ & 0.23 \\
Age (year) & $59 \pm 12$ & $60 \pm 13$ & $58 \pm 13$ & 0.68 \\
Weight (kg) & $73 \pm 14$ & $74 \pm 17$ & $72 \pm 15$ & 0.83 \\
Height (cm) & $166 \pm 8$ & $164 \pm 7$ & $164 \pm 10$ & 0.56 \\
BMI (kg/m $\left.{ }^{2}\right)$ & $27 \pm 4$ & $28 \pm 6$ & $27 \pm 5$ & 0.59 \\
ASA class & & & & 0.43 \\
I & $2(9 \%)$ & $8(25 \%)$ & $9(29 \%)$ & \\
II & $16(70 \%)$ & $20(63 \%)$ & $18(58 \%)$ & \\
III & $5(21 \%)$ & $4(12 \%)$ & $4(13 \%)$ & \\
Type of surgery & & & & 0.12 \\
$\quad$ Urological $(n)$ & 3 & 8 & 4 & \\
$\quad$ Gynecological $(n)$ & 11 & 14 & 19 & \\
Visceral $(n)$ & 12 & 11 & 8 & \\
\hline
\end{tabular}

BMI: body mass index; ASA: American Society of Anesthesiologists. groups. Specifically, there was no difference in age range between the three groups.

The level of insertion of the epidural catheter was low thoracic (Th9-Th12), with no difference in the three groups $(P=0.19)$. No cases of accidental dural puncture occurred. At the time of surgery, patients received the same amount of intravenous sufentanil $(25 \pm 11 \mu \mathrm{g}$ in the $1.5 \mathrm{mg} / \mathrm{ml}$ group, $22 \pm 15 \mu \mathrm{g}$ in the $5 \mathrm{mg} / \mathrm{ml}$ group and $20 \pm 8 \mu \mathrm{g}$ in the $7.5 \mathrm{mg} / \mathrm{ml}$ group, $P=0.28$ ). There was a small difference between groups in perioperative epidural levobupivacaine used $(54 \pm 19 \mathrm{mg}$ in the $1.5 \mathrm{mg} / \mathrm{ml}$ group, $57 \pm 20 \mathrm{mg}$ in the $5 \mathrm{mg} / \mathrm{ml}$ group and $45 \pm 11 \mathrm{mg}$ in the $7.5 \mathrm{mg} / \mathrm{ml}$ group, $P=0.024)$. Mean upper level of sensory blockade at the different time points after surgery is illustrated in Fig. 1. Sensory block was more extensive in the $1.5 \mathrm{mg} / \mathrm{ml}$ group (Th7) compared with the two other groups (Th9) $(P<0.001)$. We observed a non-significant decline in the upper sensory block after $28 \mathrm{~h}$ in the $1.5 \mathrm{mg} / \mathrm{ml}$ group.

Figure 2 shows VAS pain scores during the first 48 post-operative hours in the three groups. GLM statistics of the VAS scores for pain at rest did not show any difference between the three groups. The values of the pain indicators are displayed in Table 2. AUC, VAS max, mean VAS and PVAS $>3$ were similar in the three groups. We found no relationship between the type of surgery and the efficacy of pain relief.

Post-operative analgesic consumption is displayed in Table 2. Propacetamol was given to all patients and keterolac was administered to $25(96 \%)$ patients in the $1.5 \mathrm{mg} / \mathrm{ml}$ group, $28(85 \%)$ in the $5 \mathrm{mg} / \mathrm{ml}$ group and $26(84 \%)$ patients in the $7.5 \mathrm{mg} / \mathrm{ml}$ group $(P=0.30)$.

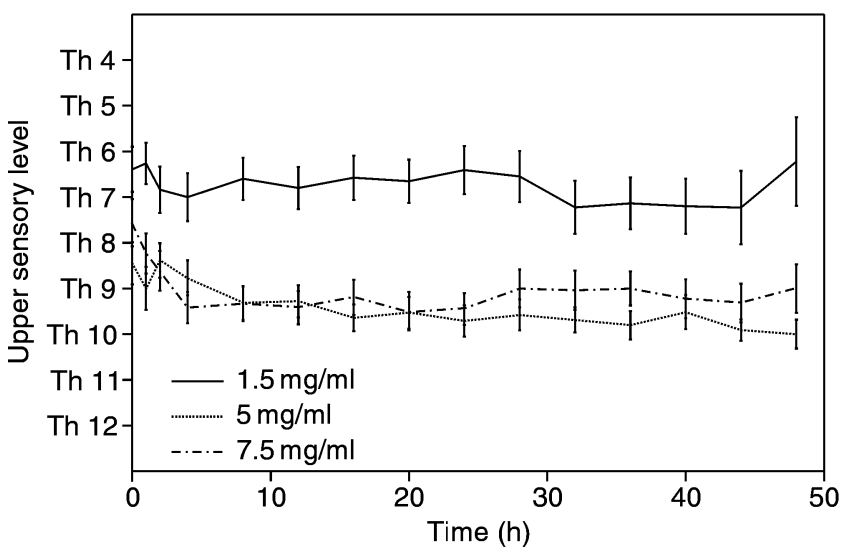

Fig. 1. Mean upper sensory dermatomal level in the three groups of patients during the 48-h (h) study period. Upper sensory levels were higher in the low concentration group when compared with the two other groups $(P<0.001$ at all time points, general linear model statistics). Concentration $(1.5,5$ and $7.5 \mathrm{mg} / \mathrm{ml}$ ) refers to levobupivacaine. Th: thoracic. 


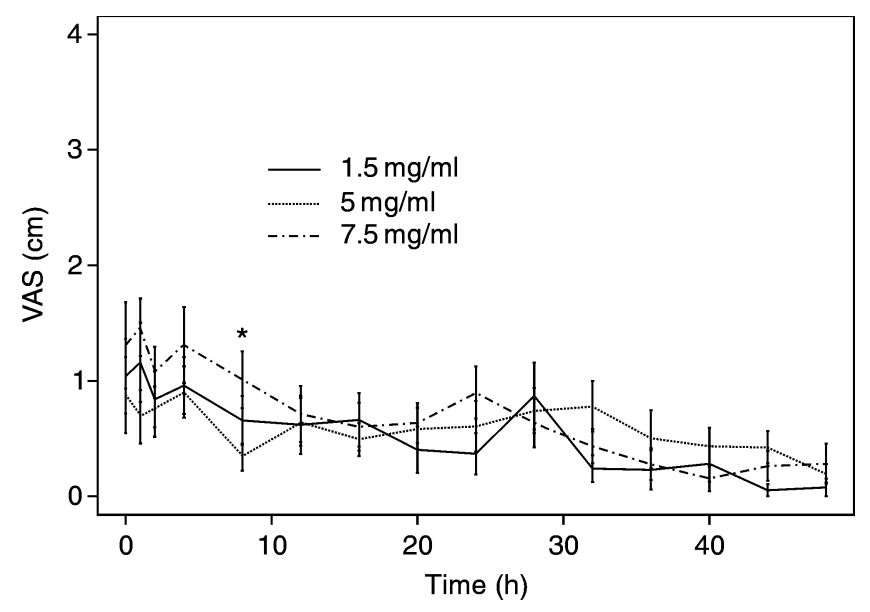

Fig. 2. Mean visual analogue scale (VAS) scores expressed in centimeter $(\mathrm{cm})$ in the three groups of patients during the 48-h study (h) period. No significant difference was found between the three groups of patients (general linear model statistics). Concentration $(1.5,5$ and $7.5 \mathrm{mg} / \mathrm{ml})$ refers to levobupivacaine. ${ }^{*} \mathrm{P}<0.05$ (ANOVA test).

Rescue analgesia, represented by morphine consumption (PCA), was similar in the three groups. In the first $24 \mathrm{~h}$, the mean consumption of morphine was $10.7 \pm 10.1 \mathrm{mg}$ in the $1.5 \mathrm{mg} / \mathrm{ml}$ group, compared with $13.0 \pm 12.0 \mathrm{mg}$ for the $5 \mathrm{mg} / \mathrm{ml}$ group and $16.1 \pm 11.7 \mathrm{mg}$ in the $7.5 \mathrm{mg} / \mathrm{ml}$ group $(P=0.16)$. In the second post-operative day, morphine use was reduced to $8.0 \pm 7.1 \mathrm{mg}$ in the $1.5 \mathrm{mg} / \mathrm{ml}$ group vs. $4.8 \pm 6.2 \mathrm{mg}$ in the $5 \mathrm{mg} / \mathrm{ml}$ group and $5.3 \pm 6.0 \mathrm{mg}$ in the $7.5 \mathrm{mg} / \mathrm{ml}$ group $(P=0.09)$. No life-threatening respiratory events associated with opioid administration were reported during the study period.

Nine $(35 \%)$ patients in the $1.5 \mathrm{mg} / \mathrm{ml}$ group suffered nausea compared with $4(12 \%)$ in the $5 \mathrm{mg} / \mathrm{ml}$ group and $3(10 \%)$ in the $7.5 \mathrm{mg} / \mathrm{ml}$ group $(P=0.028)$. Vomiting was observed in 2 patients in the $1.5 \mathrm{mg} / \mathrm{ml}$ group, in 1 in each other group $(P=0.63)$.

Motor blockade was consistently low in all patients (mean Bromage scale inferior to I) without any difference between the groups. There was a significant difference in haemodynamic parameters: systolic and diastolic blood pressures were lower in the $1.5 \mathrm{mg} / \mathrm{ml}$ group (Fig. $3 ; P<0.001$ ). GLM statistics showed a highly significant time effect on the variables $(P<0.0001)$, a significantly different time pattern $(P<0.001)$ as well as significantly different overall means of the groups $(P<0.001)$. No relationship could be established between age and haemodynamic repercussions (odds ratio $=1.031$; confidence limits $=0.987-1.078 ; P=0.166)$. Patients with low blood pressure did not receive any antihypertensive medication in the post-operative period. No vasoconstrictors or atropine were given for treatment of hypotension or bradycardia during the study period. No sedation, respiratory depression or pruritus was observed in any patient.

All patients of the three groups were satisfied or very satisfied regarding the quality of pain management.

\section{Discussion}

The results of the present study confirm that altering the concentration and the volume of levobupivacaine solution resulted in the same quality of analgesia after thoracic epidural administration of an identical amount of the local anaesthetic. These results are in line with previous studies, supporting the view that the quality of epidural analgesia depends on the total mass of local anaesthetic and not on the volume or concentration $(2,6,9,20,21)$. The haemodynamic

Table 2

\begin{tabular}{|c|c|c|c|c|}
\hline Variable & $\begin{array}{l}1.5 \mathrm{mg} / \mathrm{ml} \\
(n=26)\end{array}$ & $\begin{array}{l}5 \mathrm{mg} / \mathrm{ml} \\
(n=33)\end{array}$ & $\begin{array}{l}7.5 \mathrm{mg} / \mathrm{ml} \\
(n=31)\end{array}$ & $P$-value \\
\hline $\operatorname{AUC}\left(\mathrm{cm}^{2}\right)$ & $23.1 \pm 29.3$ & $26.7 \pm 29.0$ & $30.3 \pm 34.4$ & 0.68 \\
\hline VAS max (cm) & $2.2 \pm 1.6$ & $2.4 \pm 2.0$ & $2.7 \pm 1.9$ & 0.60 \\
\hline VAS mean (cm) & $0.5 \pm 0.7$ & $0.6 \pm 0.6$ & $0.7 \pm 0.7$ & 0.70 \\
\hline PVAS $>3(h)$ & $2.0 \pm 6.1$ & $1.5 \pm 3.4$ & $2.0 \pm 4.9$ & 0.91 \\
\hline Morphine $24 \mathrm{~h}(\mathrm{mg})$ & $10.7 \pm 10.1$ & $13.0 \pm 12.0$ & $16.1 \pm 12.0$ & 0.16 \\
\hline Propacetamol $48 \mathrm{~h}(\mathrm{~g})$ & $8 \pm 0$ & $8 \pm 0$ & $7.7 \pm 1.4$ & 0.39 \\
\hline NSAIDs $(n)$ & $25(96 \%)$ & $28(85 \%)$ & $26(84 \%)$ & 0.30 \\
\hline Anti-emetic drugs $(n)$ & $4(15 \%)$ & $4(12 \%)$ & $4(13 \%)$ & 0.93 \\
\hline
\end{tabular}

AUC: area under the visual analogue scale (VAS) time curve; PVAS > 3: persistence of VAS over $3 \mathrm{~cm}$; NSAIDs: non-steroidal antiinflammatory drugs. 

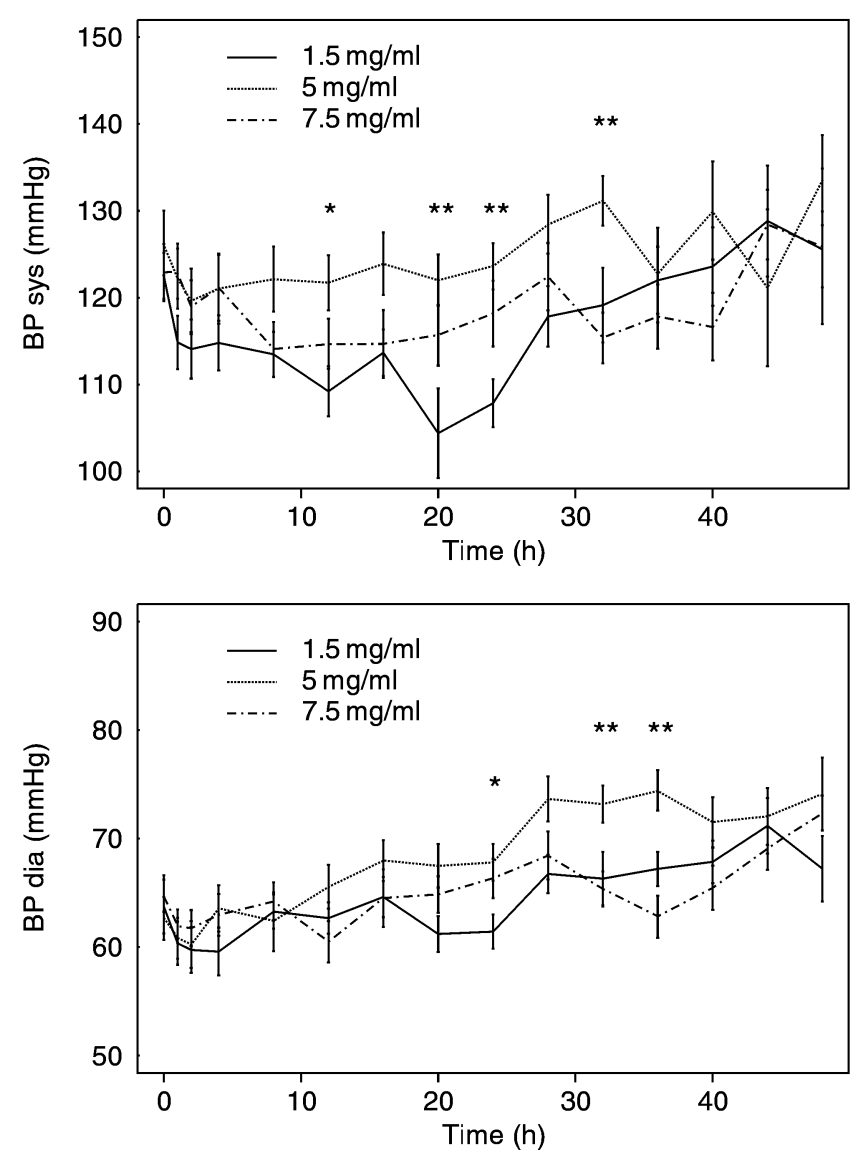

Fig. 3. Mean systolic (sys) and diastolic (dia) blood pressure (BP) in the three groups of patients during the 48-h (h) study period. Systolic and diastolic blood pressure expressed in $\mathrm{mmHg}$ was lower in the $1.5 \mathrm{mg} / \mathrm{ml}$ group when compared with the two other groups at different time points $(P=0.0044$, general linear model statistics). Concentration $(1.5,5$ and $7.5 \mathrm{mg} / \mathrm{ml})$ refers to levobupivacaine. ${ }^{*} \mathrm{P}<0.05 ;{ }^{* *} \mathrm{P}<0.01$ (ANOVA test).

stability profile seems to be more stable in the higher concentration groups. We used plain levobupivacaine $5 \mathrm{mg} / \mathrm{ml}$ and $7.5 \mathrm{mg} / \mathrm{ml}$ with continuous epidural infusions at a low thoracic level. These concentrations were selected to maximize the analgesic effects of the local anaesthetic in the thoracoabdominal somatosensory distribution (22). Lower limb motor block was consistently low in all patients and we did not observe any difference between the three groups as described in our previous study (9). The thoracic approach minimizes motor and sympathetic blockade of the lower limbs and could explain the low incidence of side-effects (23). Avoidance of epidural opioid may have contributed to the absence of pruritus, sedation and respiratory depression. The incidence of nausea was higher in the $1.5 \mathrm{mg} / \mathrm{ml}$ group. Patients were homogeneous regarding major risk of post-operative nausea and vomiting (PONV), e.g. gender, type of anaesthesia and surgery, pain, morphine consumption and they received the same anti-emetic prophylaxis $(16,24)$. Therefore we hypothesized that a higher upper level of the block (Th7) and a significantly lower blood pressure in this group could have induced more nausea (25). The high infusion rate $(10 \mathrm{ml} / \mathrm{h})$ in the $1.5 \mathrm{mg} / \mathrm{ml}$ group explained the wider cephalad extend of the sensory block. An upper level of Th7, about three segment levels higher than needed for low abdominal surgery, was determined by the study design of the trial. These results do not support Bromage's findings that the spread of analgesia is independent of the volume. Obviously the mass of the local anaesthetic defines the quality of analgesia (6). These results are in accordance with other studies $(2,4,9)$. In the post-operative period, Laveaux et al. (10) observed that the analgesic efficacy and the occurrence of side-effects of a continuous thoracic epidural infusion of bupivacaine with sufentanil at high concentration/low volume vs. low concentration/high volume were similar. These authors concluded that the total dose of the local anaesthetic was more important than the concentration or the volume of the solution. Similar results were reported by Mogensen et al. (11) and Scott et al. (26)

However, as mentioned in the introduction section, there are some discrepancies in the literature concerning analgesic effect of the concentration of local anaesthetics. After thoracic surgery, Snijdelaar et al. (12) found better analgesia with high volume/low concentration of epidural local anaesthetics compared with a low volume/high concentration. In their study, they used a smaller amount of bupivacaine, i.e. $7.5-10 \mathrm{mg} / \mathrm{h}$ compared with the $15 \mathrm{mg} / \mathrm{h}$ in our study. This fact could contribute to the higher incidence of pain at rest their patients experienced. Liu et al. (27), using patient-controlled epidural analgesia (PCEA), observed that lesser concentrations of a similar amount of epidural ropivacaine/fentanyl provide equal analgesia with less motor blockade after lower abdominal surgery. Epidural catheters were placed at the Th12-L2 interspace. Placement of catheters in proximity of lumbar spinal segments increases the risk of motor block when compared with a more cephalad approach (28). Whiteside et al. (29), using the same association of drugs after gynaecological surgery, showed that a low concentration/ high volume PCEA appears satisfactory in treating post-operative pain and reducing the dose of the drugs used in comparison with a low volume/high concentration. Our study differs considerably because we used a continuous infusion of the local anaesthetic rather than PCEA, and we did not add any 
opioids epidurally in order to focus only on local anaesthetic action. Administration of a high volume of fentanyl associated with the local anaesthetic could produce more extensive sensory block as a result of greater anatomic spread and interaction with opiate receptors $(26,28)$. Opioids also limit the regression of the sensory block observed with local anaesthetics alone and improve the quality of pain relief (30). This fact makes a comparison with our results difficult.

The most important limitation of our study design is that only pain at rest was assessed. New experiments must focus on pain during mobilization or coughing. Furthermore, our patients received multimodal analgesia and were treated with systemic analgesics that may have masked slight differences in the intensity of rest pain between the three groups. Further studies should also examine quality of analgesia with other infusion rate modalities considering that patients in the low concentration levobupivacaine group, i.e. $1.5 \mathrm{mg} / \mathrm{ml}$, should have had a lower infusion rate than that determined by the study design. It should be noted that the plain 5 and $7.5 \mathrm{mg} / \mathrm{ml}$ levobupivacaine solutions are ready to use. Thereby the risk of administration errors decreases as well as the nursing time and pharmacy preparation costs.

In conclusion, continuous $5 \mathrm{mg} / \mathrm{ml}$ and $7.5 \mathrm{mg} / \mathrm{ml}$ levobupivacaine given epidurally at the thoracic level were equally effective as the same dose of a 1.5-mg/ $\mathrm{ml}$ solution in achieving adequate analgesia and with better haemodynamic stability, lower cephalad extent of sensory block and reduced incidence of nausea.

\section{References}

1. Scott DB, McClure JH, Giasi RM, Seo J, Covino BG. Effects of concentration of local anaesthetic drugs in extradural block. Br J Anaesth 1980; 52: 1033-7.

2. Duggan J, Bowler GMR, McClure JH, Wildsmith JAW. Extradural block with bupivacaine: Influence of dose, volume, concentration and patient characteristics. Br J Anaesth 1988; 61: 324-31.

3. Galindo A, Benavides O, Ortega de Munos S, Bonilla O, Pena R. Comparison of anesthetic solutions used in lumbar and caudal peridural anesthesia. Anesth Analg 1978; 57: 175-9.

4. Liu SS, Ware PD, Rajendram S. Effects of concentration and volume of 2-chloroprocaine on epidural anesthesia in volunteers. Anesthesiology 1997; 86: 1288-93.

5. Sakura S, Sumi M, Kushizaki H, Saito Y, Kosaka Y. Concentration of lidocaine affects intensity of sensory block during lumbar epidural anesthesia. Anesth Analg 1999; 88: 123-7.

6. Bromage PR. Mechanism of action of extradural analgesia. Br J Anaesth 1975; 47: 199-211.

7. Pierce ET, Denson DD, Essel SK, Santos DJ, Edstrom HH. The effect of rate of infusion on continuous epidural analgesia for labor and delivery. Reg Anesth 1989; 14: 31-34.
8. Renck H, Edström H, Kinnberger B, Brandt G. Thoracic epidural analgesia. II. Prolongation in the early postoperative period by continuous injection of $1.0 \%$ bupivacaine. Acta Anaesthesiol Scand 1976; 20: 47-56.

9. Dernedde M, Stadler M, Bardiau F, Boogaerts JG. Continuous epidural infusion of large concentration/small volume versus small concentration/large volume of levobupivacaine for postoperative analgesia. Anesth Analg 2003; 96: 796-801.

10. Laveaux MM, Hasenbos MAWM, Harbers JBM, Liem T. Thoracic epidural bupivacaine plus sufentanil: high concentration/low volume versus low concentration/high volume. Reg Anesth 1993; 18: 39-43.

11. Mogensen T, Scott NB, Hjortso NC, Lund C, Kehlet H. The influence of volume and concentration of bupivacaine on regression of analgesia during continuous postoperative epidural infusion. Reg Anesth 1988; 13: 122-125.

12. Snijdelaar DG, Hasenbos MA, van Egmond J, Wolff AP, Liem TH. High thoracic epidural sufentanil with bupivacaine. Continuous infusion of high volume versus low volume. Anesth Analg 1994; 78: 490-4.

13. Boogaerts JG, Vanacker E, Seidel L, Albert A, Bardiau F. Assessment of postoperative nausea using a visual analogue scale. Acta Anaesthesiol Scand 2000; 44: 470-4.

14. Murdoch JAC, Dickson UK, Wilson PA, Berman JS, Gad-Elrab RR, Scott NB. The efficacy and safety of three concentrations of levobupivacaine administered as a continuous epidural infusion in patients undergoing orthopedic surgery. Anesth Analg 2002; 94: 438-44.

15. Daoud Z, Collis RE, Ateleamu B, Mapleson WW. Evaluation of S1 motor block to determine a safe reliable test dose for epidural analgesia. Br J Anaesth 2002; 89: 442-5.

16. Boogaerts JG, Bardiau FM, Seidel L, Albert A, Ickx BE. Tropisetron in the prevention of postoperative nausea and vomiting. J Clin Anesth 2000; 12: 402-8.

17. Bardiau FM, Braeckman MM, Seidel L, Albert A, Boogaerts JG. Effectiveness of an acute pain service inception in a general hospital. J Clin Anesth 1999; 11: 583-9.

18. Bromage PR. A comparison of hydrochloride and carbon dioxide salts of lidocaine and prilocaine in epidural analgesia. Acta Anaaesthesiol Scand 1965: 20 (Suppl. 16): 55S-69S.

19. Braeckman MM, Bardiau FM, Boogaerts JG. Sample size and power analysis in acute pain studies. Dolor 1998; 13: 46.

20. Grundy EM, Ramamurthy S, Patel KP, Mani M, Winnie AP. Extradural analgesia revisited. A statistical study. $\mathrm{Br} J$ Anaesth 1978; 50: 805-9.

21. Kaneko T, Iwama $H$. The association between injected volume of local anesthetic and spread of epidural anesthesia: a hypothesis. Reg Anesth Pain Med 1999; 24: 153-7.

22. Green R. Post-operative analgesia. The use of continuous drip epidural block. Anaesthesia 1966; 21: 372-8.

23. Wheatley RG, Schug SA, Watson D. Safety and efficacy of postoperative epidural analgesia. Br J Anaesth 2001; 87: 47-61.

24. Stadler M, Bardiau F, Seidel L, Albert A, Boogaerts JG. Difference in risk factors for postoperative nausea and vomiting. Anesthesiology 2003; 98: 46-52.

25. Rabey PG, Smith G. Anaesthetic factors contributing to postoperative nausea and vomiting. Br J Anaesth 1992; 69 (Suppl. 1): 40S-5S.

26. Scott DA, Chamley DM, Mooney PH, Deam RK, Mark AH, Hägglöf B. Epidural ropivacaine infusion for postoperative analgesia after major lower abdominal surgery - a dose finding study. Anesth Analg 1995; 81: 982-6.

27. Liu SS, Moore JM, Luo AM, Trautman WJ, Carpenter HL. Comparison of three solutions of ropivacaine-fentanyl for 


\section{Dernedde et al.}

postoperative patient controlled epidural analgesia. Anesthesiology 1999; 90: 727-33.

28. Liu SS, Allen HW, Olsson GL. Patient-controlled epidural analgesia with bupivacaine and fentanyl on hospital wards. Prospective experience with 1,030 surgical patients. Anesthesiology 1998; 88: 888-95.

29. Whiteside R, Jones D, Bignell S, Lang C, Lo SK. Epidural ropivacaine with fentanyl following major gynaecological surgery: the effect of Volume and concentration on pain relief and motor impairment. Br J Anaesth 2000; 84: 720-4.

30. Jorgensen H, Wetterlev J, Moiniche S, Dahl JB. Epidural local anaesthetics versus opioid-based analgesic regimens on postoperative gastrointestinal paralysis, $\mathrm{PONV}$ and pain after abdominal surgery. Cochrane Database Syst Rev 2000; 4: CD001893.

Address:

Mira Dernedde

Department of Anaesthesiology

University Hospital Centre

92 boulevard P. Janson

6000 Charleroi

Belgium

e-mail: mira.dernedde@chu-charleroi.be 